\title{
Critical appraisal of Rome IV criteria: hypersensitive esophagus does belong to gastroesophageal reflux disease spectrum
}

\section{Leonardo Frazzonia, Marzio Frazzoni ${ }^{b}$, Nicola de Bortolic, Salvatore Toloned, Irene Martinuccic, Lorenzo Fuccio ${ }^{a}$, Vincenzo Savarino ${ }^{e}$, Edoardo Savarino ${ }^{f}$}

University of Bologna; Baggiovara Hospital, Modena; University of Pisa; $2^{\text {nd }}$ University of Napoli; University of Genova; University of Padova, Italy

\section{Abstract}

${ }^{a}$ Department of Medical and Surgical Sciences, University of Bologna (Leonardo Frazzoni, Lorenzo Fuccio); ${ }^{b}$ Digestive Pathophysiology Unit, Baggiovara Hospital, Modena (Marzio Frazzoni); 'Department of Translational Research and New Technology in Medicine and Surgery, University of Pisa (Nicola de Bortoli, Irene Martinucci); ${ }^{\mathrm{d}}$ General and Bariatric Surgery Unit, Department of Surgery, $2^{\text {nd }}$ University of Napoli (Salvatore Tolone); ${ }^{\mathrm{e}}$ Gastroenterology Unit, Department of Internal Medicine, University of Genova (Vincenzo Savarino); ${ }_{\mathrm{f}}^{\mathrm{f}}$ Gastroenterology Unit, Department of Surgery, Oncology and Gastroenterology, University of Padova (Edoardo Savarino), Italy

Conflict of Interest: None

Correspondence to: Dr. Marzio Frazzoni, Fisiopatologia Digestiva, AOU Modena, Ospedale Baggiovara, Viale Giardini 1355, 41100 Modena, Italy, e-mail marziofrazzoni@gmail.com

Received 18 August 2017; accepted 17 September 2017; published online 10 October 2017

DOI: https://doi.org/10.20524/aog.2017.0199

\section{Introduction}

Gastroesophageal reflux disease (GERD) is characterized by troublesome symptoms or mucosal lesions due to reflux of gastric contents into the esophagus. The typical GERD syndrome is characterized by heartburn and regurgitation, and proton pump inhibitor (PPI) therapy represents the mainstay of medical treatment for typical GERD, with very high efficacy in heartburn relief and healing of erosive reflux disease (ERD) [1-3]. Non-ERD (NERD) has been defined by endoscopy-negative heartburn (ENH) and evidence of a direct link of the symptom with reflux, as shown by $\mathrm{pH}$ or impedance$\mathrm{pH}$ monitoring and/or response to anti-reflux therapy [4]. Since endoscopy shows reflux esophagitis in less than one third of patients with heartburn, symptom remission with a PPI trial has been considered sufficient to confirm a diagnosis of GERD [1-3]. 
The Rome Committees began in the mid 1980s as a series of meetings that developed consensus criteria for research purposes and care of patients with functional gastrointestinal disorders [5]. Functional heartburn (FH) has been one of the most debated conditions addressed by the Rome experts [6-8]. According to the Rome II criteria [6], patients with ENH were classified as FH or NERD on the basis of normal or pathologic acid exposure time (AET), as detected by traditional ambulatory esophageal $\mathrm{pH}$ monitoring. The definition of GERD was expanded in the Rome III criteria [7] to include patients with hypersensitive esophagus (HE), defined as satisfactory evidence of a relationship between heartburn and acid reflux events, based either on a $\mathrm{pH}$ study or on symptom relief from a PPI trial. More recently, the Rome IV Committee proposed that HE be separated from GERD, with this subgroup of patients being classified within the realm of functional esophageal disorders along with, but separate from $\mathrm{FH}$ [8].

\section{GERD diagnosis: the real challenge}

A gold standard for GERD diagnosis has not yet been widely recognized [1-4]. Since in the vast majority of patients with reflux symptoms visible mucosal lesions are not detected on upper gastrointestinal endoscopy, reflux monitoring is required to objectively document GERD in the vast majority of cases [1-4]. By means of $\mathrm{pH}$ monitoring, the total percentage of time with $\mathrm{pH}<4.0$, namely the acid exposure time (AET), can be assessed and when abnormal values are found GERD is confirmed [4]. However, the limitations of AET have long been documented, consisting in high variability of normative values and false negative results in up to $30 \%$ of patients with reflux esophagitis $[9,10]$. To overcome these limitations, symptom/ reflux association indexes, namely symptom index (SI) and symptom-association probability (SAP), were developed to document a cause-and-effect relationship between acid reflux episodes and symptoms in endoscopy-negative, $\mathrm{pH}$-negative heartburn cases [9]. The diagnostic category of $\mathrm{HE}$ [7] or reflux hypersensitivity [8] has been proposed in order to better identify $\mathrm{pH}$-negative cases with positive SI or SAP.

In recent years, in vitro studies have shown that the proteolytic activity of pepsins is necessary for reflux-induced esophageal mucosa damage to occur, and such activity is maintained up to pH 6.0 units [11]. Moreover, it has been observed that healing of mucosal breaks occurs through reparative processes that are inhibited at $\mathrm{pH}<6.5$ units [12]. Refluxes with $\mathrm{pH}>4.0$ units can be reliably assessed with combined impedance-pH monitoring, which detects all reflux episodes by impedance changes and has been regarded as the gold standard for a comprehensive assessment of reflux $[13,14]$. With the advent of impedance$\mathrm{pH}$ monitoring, SAP and SI have been used to demonstrate a direct link between non-acid reflux episodes and symptoms and to increase our ability to diagnose GERD, showing a higher diagnostic gain on PPI therapy [15-18]. Electron [19] and light [20] microscopy studies have shown that microscopic esophagitis is much more frequently detected in patients with $\mathrm{HE}$, as defined by SAP/SI positivity, than in FH cases. However, the major problem with symptom/reflux association indexes is that they are overly patient-dependent: patients often do not perceive symptoms during the impedance-pH study or admit inaccurate symptom recording. Furthermore, SAP/SI positivity is reportedly determined by chance when reflux rates are low [21]. Impedance monitoring also allows assessment of the total number of reflux events, independently of $\mathrm{pH}$. The total number of reflux events is scarcely affected by PPI therapy [22] and abnormal values at on-PPI testing can predict abnormal AET at off-therapy evaluation [23]. By using on-PPI impedance-pH monitoring, it has been shown that weakly acidic refluxes represent the vast majority of reflux events and of symptom-associated refluxes in patients with PPI-refractory typical GERD [24]: notably, in parallel with complete symptom relief, they are nearly abolished by successful laparoscopic fundoplication [25-27], and the results of these studies represent direct in vivo evidence that weakly acidic refluxes have a key role in the pathogenesis of PPI refractoriness.

Assessment of AET, SAP, SI and number of reflux events represents the traditional approach to analysis of impedance$\mathrm{pH}$ tracings, quite similar to that of $\mathrm{pH}$ monitoring. In recent years, innovative approaches have been proposed. Baseline impedance can be accurately measured in impedance tracings and low values reflect reflux-induced impairment of mucosal integrity, even in the absence of macroscopic damage [28] and without circadian variations [29]. It has been shown that the mean of three 10-min nighttime periods, selected to avoid refluxes, swallows and $\mathrm{pH}$ drops, accurately reflects the 6-h nocturnal bedtime period [30]. Interestingly, similar lower values of nocturnal baseline impedance have been found in SAP/ SI positive and SAP/SI negative patients with PPI-responsive heartburn as opposed to SAP/SI negative patients with PPIrefractory heartburn and normal AET [31], suggesting that SAP/SI positivity does not accurately distinguish $\mathrm{HE}$ from $\mathrm{FH}$. In addition to detection of all types of reflux events, impedance monitoring also allows the assessment of clearance of refluxate. Volume clearance consists of a secondary peristaltic wave, elicited by esophageal stretch receptors and removes around $90 \%$ of the refluxate, determining the end of a reflux episode [32]. Chemical clearance consists of a salivary swallow, elicited by a post-reflux esophago-salivary vagal reflex [33] and delivering salivary bicarbonate and epidermal growth factor to the esophagus, thus augmenting $\mathrm{pH}$ and hastening repair of reflux-induced mucosal damage. An impedance drop originating in the upper esophagus and reaching the lower part of the organ signals the peristaltic transit of saliva and has been defined as a post-reflux swallow-induced peristaltic wave (PSPW). An index of chemical clearance, namely the PSPW index, can be obtained by dividing the number of refluxes followed by a PSPW within $30 \mathrm{sec}$ by the number of total refluxes [34]. In a pilot single-center study, lower values of PSPW index at off-PPI impedance-pH testing were found in ERD as compared to NERD cases and in both GERD subgroups as opposed to healthy controls; similar results were observed at on-PPI testing comparing PPI-refractory ERD and NERD patients and both with FH cases [34].

In a multicenter off-PPI impedance-pH study, the PSPW index and MNBI distinguished 221 NERD patients from 50 healthy controls better than AET; a significant direct 
correlation between the two parameters was found and an excellent area under the curve (AUC) of the PSPW index at receiver operating characteristic (ROC) analysis (0.977) was observed [35]. NERD was defined on the basis of a 6-month history of recurrent troublesome heartburn, repeatedly abolished by PPI courses. Notably, only 118 of 221 (53\%) NERD cases were pH-positive (abnormal AET), while in the $103 \mathrm{pH}$-negative NERD cases (normal AET) the diagnostic accuracy of PSPW index and MNBI was $86 \%$ and $67 \%$ in the $65 \mathrm{SAP} / \mathrm{SI}$ positive cases and $82 \%$ and $76 \%$ in the $38 \mathrm{SAP} / \mathrm{SI}$ negative cases, respectively. NERD diagnosis was confirmed by conventional $\mathrm{pH}$-only criteria, namely AET and SAP/ SI positivity for acid refluxes, in $75 \%$ of cases only, and by impedance-pH criteria, including PSPW index and MNBI, in $98 \%$ of cases $(\mathrm{P}=0.001)$ [35].

In a subsequent off-PPI impedance-pH study, $125 \mathrm{pH}$ positive and $108 \mathrm{pH}$-negative PPI-responsive NERD patients were compared to $70 \mathrm{FH}$ patients, defined by ENH totally refractory to 8-week high-dose PPI therapy with normal AET and negative SAP/SI [36]. PSPW index and MNBI were significantly lower in $\mathrm{pH}$-positive than in $\mathrm{pH}$-negative NERD cases, and in both groups compared to FH cases. By multivariate logistic regression analysis, PSPW index and MNBI were found to be independent predictors of HE, defined by normal AET and definitely PPI-responsive heartburn, i.e., heartburn repeatedly responsive to PPI courses and quickly recurring after PPI withdrawal [36]. SAP/SI positivity was found in $62 \%$ of $\mathrm{HE}$ patients, whereas PSPW index/MNBI positivity was found in $92 \%$ of them, affording a significant $(\mathrm{P}<0.0001)$ diagnostic gain in one third of cases [36]. The combined assessment of PSPW index and MNBI provided excellent separation of $\mathrm{HE}$ from $\mathrm{FH}$ on ROC analysis (AUC 0.957) [36].

Moreover, PSPW index and MNBI have been proved useful at on-PPI impedance-pH testing [37]. In a multicenter study conducted in 189 patients with PPI-refractory heartburn, i.e., troublesome heartburn persisting despite 8-week high-dose PPI therapy, significantly lower values of PSPW index and MNBI were found in patients with persisting reflux esophagitis than in those with healed reflux esophagitis and NERD, and in all these three GERD subgroups than in cases with FH [37]. On ROC analysis, comparing NERD with FH, the AUC of PSPW index and MNBI was 0.886 and 0.677 , respectively [37]. Notably, in multivariate logistic regression analysis the PSPW index was an independent predictor of PPI-refractory GERD, confirmed by objectively documented 3 -year positive surgical outcome [37]. Interestingly, Patel et al showed that low MNBI values, measured at off-PPI impedance-pH monitoring in accordance with the method proposed by Martinucci et al [30], represent an independent predictor of GERD response to medical as well as surgical anti-reflux treatment [38].

Furthermore, in a very recent multicenter off-therapy impedance-pH study, 317 patients with PPI-responsive were compared to 108 patients with PPI-refractory heartburn [39]. On multivariate logistic regression analysis, AET, MNBI, and PSPW index were the only factors independently associated with PPI responsiveness [39]. On ROC analysis, PSPW index (AUC 0.794) and MNBI (AUC 0.742), both separately and combined (AUC 0.811), were more efficient predictors of PPI-responsiveness than AET (AUC 0.687) [39], overcoming its well documented day-to-day variability [40].

Taken together, the results of the studies evaluating MNBI and PSPW index [30,31,34-39] show that these novel impedance parameters provide a significant diagnostic yield compared with conventional AET, SAP, SI, and number of reflux events, and should be routinely adopted for both research and clinical purposes. Low values of PSPW index reflect impairment of chemical clearance, with consequent stasis of toxic refluxate within the esophagus and loss of mucosal integrity, documented by the directly related low values of MNBI: these mechanisms can explain the increased perception of reflux events and the PPI responsiveness in patients with HE, suggesting that they really belong to the GERD spectrum and cannot be displaced to the realm of functional gastrointestinal disorders.

\section{The pitfalls of Rome IV}

The major problem with the Rome IV criteria is that only acid exposure was considered in the interplay between heartburn and GERD [8]. Accordingly, NERD was defined on the basis of abnormal AET only, whereas HE, characterized by positive SAP/SI and normal AET, was considered as separate from GERD (in contrast to Rome III [7]) and was included within the spectrum of functional esophageal disorders [8]. Justification for the criteria change are that "although patients with symptom/reflux correlation to physiologic reflux events may respond to PPI therapy, the most logical pathophysiologic explanation is consistent with the current understanding of visceral hypersensitivity and mechanisms of peripheral or central sensitization." On the other hand, the Rome IV Committee stated that "lack of response to PPI therapy should be considered as an important diagnostic criterion to establish that symptoms are not related to gastroesophageal reflux. Clinical experience suggests that a lack of response to PPI probably has a high negative predictive value for the diagnosis of GERD”. However, evidence-based medicine does not rely on logical concepts or clinical experience.

Indeed, the concept of visceral hypersensitivity as the dominant mechanism of HE is contradicted by many studies. Patients with FH overlap with functional dyspepsia [41] and irritable bowel syndrome [42] significantly more often than those with HE and NERD. The Rome IV Committee admitted that only one study supports the efficacy of visceral pain modulators in HE [43], but omitted to report a more recent randomized placebo-controlled trial in which imipramine and placebo were similarly ineffective in $\mathrm{HE}$ and in $\mathrm{FH}$ [44]. On the other hand, positive outcomes with medical or surgical anti-reflux treatment have been consistently reported in $\mathrm{HE}$ [25-27,38,39,45-50] and two recent consensuses recommend laparoscopic fundoplication as the treatment of choice in well-documented PPI-refractory GERD [51,52].

In contrast with Rome IV, the Montreal Global Consensus [1] and current AGA and ACG Guidelines [2,3] stated that relief of heartburn, the cardinal GERD symptom, 
with PPI therapy confirms the diagnosis of GERD. Heartburn suppression by PPIs as a diagnostic criterion for GERD in patients with ENH has been criticized by Rome IV because of the high placebo response and its limited predictive value [8]. However, the placebo response rate was less than $15 \%$ in studies of PPI therapy in patients with heartburn [53], and the response rates in ERD and NERD are similar when the NERD diagnosis is objectively documented on the basis of direct reflux testing, including abnormal AET or positive SAP/ SI [54]. Furthermore, the moderate diagnostic sensitivity of AET and SAP could have influenced the reportedly moderate diagnostic specificity of a PPI trial [55]. When a diagnostic test provides negative results, despite definite responsiveness of typical symptoms to a specific therapy, more efficient diagnostic methods need to be sought. In our studies that aimed to assess the diagnostic yield of PSPW index and MNBI $[35,36,39]$, we defined GERD in ENH patients when rapid symptom relief was achieved with PPI therapy, heartburn recurred early after PPI withdrawal, and prompt symptom suppression with repeated PPI therapy was again reported: this criterion cannot be considered simply a positive response to a PPI trial, but represents a definite PPI responsiveness. In our studies, PSPW index and MNBI were abnormal in the vast majority of definitely PPI-responsive heartburn cases with normal AET and negative SAP/SI $[35,36]$ and predicted PPI responsiveness better than AET [39]. Moreover, we have shown the pathophysiologic consistency of PSPW index and MNBI in patients with PPI-refractory heartburn by the detection of progressively lower values in NERD, healed reflux esophagitis and persistent reflux esophagitis, and significantly lower values in all these three GERD subgroups than in $\mathrm{FH}$ cases [37]. Therefore, considering the high diagnostic yield afforded by PSPW index and MNBI, we believe that analyses of these impedance parameters should become part of the diagnostic algorithm in patients with ENH [56]. Symptom/ reflux association indexes and number of reflux events should not be abandoned, however, owing to their usefulness as predictors of a favorable outcome with medical or surgical therapy [25-27,45-50]. When AET is normal, concordant SAP/SI positivity and/or concordant abnormality of PSPW index and MNBI and/or abnormal number of reflux events document $\mathrm{pH}$-negative NERD, i.e., HE, which belongs to the realm of GERD and should be managed accordingly.

The Rome IV Committee suggests that HE diagnosis requires exclusion of eosinophilic esophagitis (EoE) and major motor disorders (achalasia, esophago-gastric junction outflow obstruction, diffuse esophageal spasm, jackhammer esophagus, absent peristalsis), implying that multiple esophageal biopsies and high-resolution manometry are routinely warranted [8]. However, heartburn and chest pain in adults with EoE are not dominant or co-dominant symptoms and when present accompany dysphagia [57]; moreover, in the absence of solid food dysphagia and food impaction, high intraepithelial eosinophil counts are not specific for EoE [58] and routine esophageal biopsies are not recommended [59,60]. Esophageal manometry is routinely warranted before $\mathrm{pH}$ or impedance$\mathrm{pH}$ monitoring, for correct placement of the $\mathrm{pH}$ or impedance$\mathrm{pH}$ catheter and for exclusion of achalasia and other major esophageal motility disorders, but it should be considered that both aims can be accomplished by high-resolution as well as by conventional manometry $[61,62]$.

Summing up, neither the relevance of weakly acidic reflux in the pathogenesis of PPI-refractory GERD nor the insufficient diagnostic accuracy of conventional $\mathrm{pH}$ monitoring were adequately considered by the Rome IV Committee. In the classification scheme proposed by Rome IV, patients with PPIrefractory ENH and proven GERD should be further classified on the basis of the results of on-PPI impedance-pH testing. Indeed, on-PPI impedance-pH monitoring is regarded as the test of choice to investigate the mechanisms of PPI-refractory heartburn, i.e., poor compliance, inadequate acid suppression, high burden of weakly acidic refluxes or reflux-unrelated, namely FH [63], but cannot be based on AET alone, which has long been recognized as scarcely useful in the clinical setting of PPI refractoriness during ongoing PPI therapy [64]. The analysis of on-PPI impedance-pH tracings based on AET and SAP/SI only in patients with proven GERD would inevitably result in a reclassification of the majority of these cases as $\mathrm{FH}$, thus contradicting the previous off-PPI diagnosis of GERD. As far as unproven GERD in the Rome IV classification scheme is concerned, there is vast evidence that off-PPI $\mathrm{pH}$ monitoring cannot afford an accurate enough diagnosis of GERD and that impedance-pH monitoring represents the test of choice $[4,17,18,35,36,39]$.

GERD is a spectrum disease, ranging from NERD to ERD and Barrett's esophagus $[4,65]$. HE represents a particular NERD subgroup, distinguished from $\mathrm{FH}$ by impairment of chemical clearance and mucosal integrity [30,31,35,36,39], which explain the frequently positive response to medical and surgical anti-reflux treatment [25-27,35-37,39,45-50]. Thus, we propose an evidence-based classification scheme of $\mathrm{ENH}$, relying on impedance-pH monitoring with analysis of conventional and novel impedance-pH parameters (Fig. 1), with the cutoff values reported in Table 1 [35]. When AET is normal, concomitant abnormality of PSPW index and MNBI

Table 1 Cutoff values for impedance-pH parameters*

\begin{tabular}{lc}
\hline Parameter & Positivity \\
\hline AET & $>3.2 \%$ \\
Total refluxes & $>48$ \\
SAP & $>95 \%$ \\
SI & $>50 \%$ \\
PSPW index & $<61 \%$ \\
MNBI & $<2292 \Omega$ \\
\hline
\end{tabular}

${ }^{*}$ Established with ROC analysis comparing 50 healthy subjects with 289 GERD patients [35]. The PSPW index is calculated by dividing the number of total refluxes followed by a PSPW within $30 \mathrm{sec}$ by the number of total refluxes. The MNBI is assessed from the most distal impedance channel by selecting three 10-min nighttime recumbent periods with avoidance of reflux events, $\mathrm{pH}$ drops and swallows; the mean of the 3 measurements is then calculated manually

$R O C$, receiver operating characteristic; GERD, gastroesophageal reflux disease; AET, acid exposure time; SAP, symptom association probability; SI, symptom index; PSPW, post-reflux swallow-induced peristaltic wave; MNBI, mean nocturnal baseline impedance 


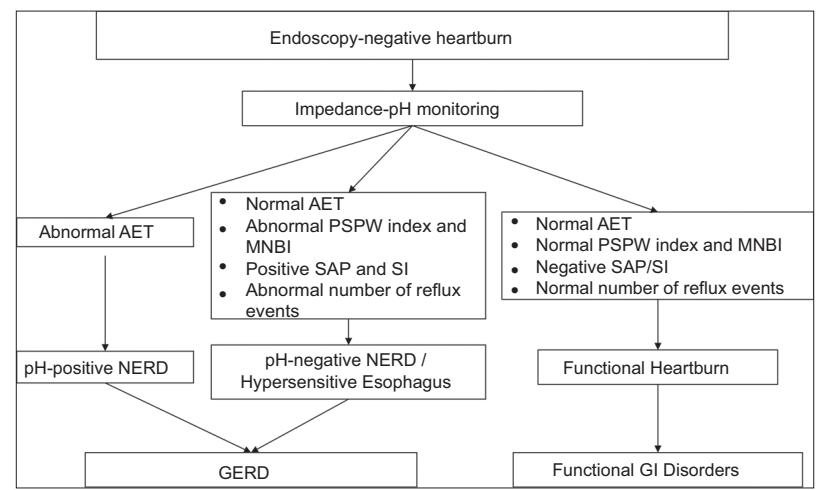

Figure 1 Classification of endoscopy-negative heartburn

The Figure suggests a classification scheme and does not represent a diagnostic algorithm

$A E T$, acid exposure time; $M N B I$, mean nocturnal baseline impedance; NERD, non-erosive reflux disease; PSPW, post-reflux swallow-induced peristaltic wave; SAP, symptom association probability; SI, symptom index; GERD, gastroesophageal reflux disease; GI, gastrointestinal

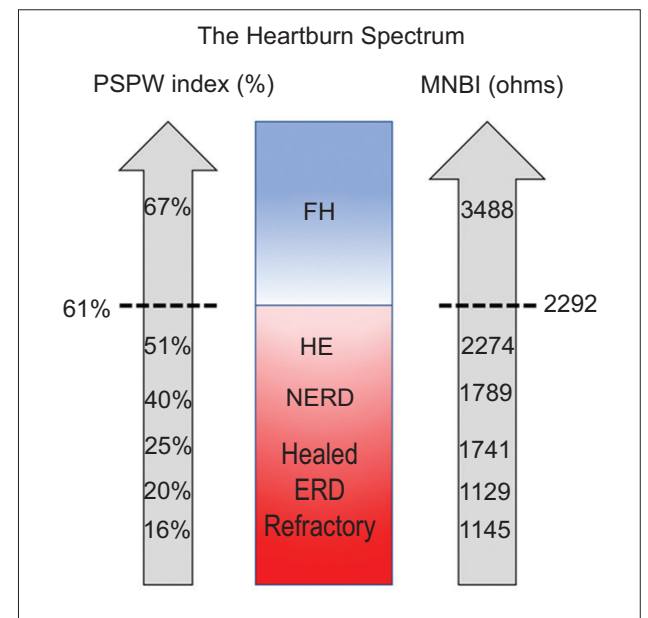

Figure 2 Median and cutoff values of PSPW index and MNBI for the various diagnostic categories in the heartburn spectrum Dotted lines indicate cutoff values

$E R D$, erosive reflux disease; $F H$, functional heartburn; $H E$, hypersensitive esophagus; MNBI, mean nocturnal baseline impedance; NERD, nonerosive reflux disease; PSPW, post-reflux swallow-induced peristaltic wave

establishes HE independently from SAP/SI or number of reflux events. Median values of PSPW index and MNBI for the various diagnostic categories in the heartburn spectrum are shown in Fig. 2.

\section{Concluding remarks}

$\mathrm{HE}$ is a category that arose from the diagnostic limitations of AET, assessed with traditional $\mathrm{pH}$ monitoring, to give a pathophysiological label to endoscopy-negative, $\mathrm{pH}$-negative heartburn. ENH patients should be classified on the basis of impedance-pH monitoring, the only method affording a comprehensive and accurate assessment of reflux. Many studies have documented that weakly acidic refluxes, which cannot be reliably measured by $\mathrm{pH}$ monitoring, play a key role in the pathogenesis of PPI-refractory reflux esophagitis and PPI-refractory ENH, and that HE, i.e., $\mathrm{pH}$-negative heartburn, responds to anti-reflux medical and surgical treatment. PSPW index and MNBI significantly increase the diagnostic yield of impedance-pH monitoring, as performed off- or on-PPI therapy. In our opinion, there is ample evidence that patients with HE should be considered within the GERD spectrum and treated accordingly.

\section{References}

1. Vakil N, van Zanten SV, Kahrilas P, Dent J, Jones R; Global Consensus Group. The Montreal definition and classification of gastroesophageal reflux disease: a global evidence-based consensus. Am J Gastroenterol 2006;101:1900-1920.

2. Kahrilas PJ, Shaheen NJ, Vaezi MF; Clinical Practice and Quality Management Committee. American Gastroenterological Association Institute technical review on the management of gastroesophageal reflux disease. Gastroenterology 2008;135:1392-1413.

3. Katz PO, Gerson LB, Vela MF. Guidelines for the diagnosis and management of gastroesophageal reflux disease. Am J Gastroenterol 2013;108:308-328.

4. Savarino E, Zentilin P, Savarino V. NERD: an umbrella term including heterogeneous subpopulations. Nat Rev Gastroenterol Hepatol 2013;10:371-380.

5. Drossman DA, Hasler WL. Rome IV - Functional GI disorders: disorders of gut-brain interaction. Gastroenterology 2016;150:1257-1261.

6. Clouse RE, Richter JE, Heading RC, Janssens J, Wilson JA. Functional esophageal disorders. Gut 1999;45(Suppl 2):II31-II36.

7. Galmiche JP, Clouse RE, Bálint A, et al. Functional esophageal disorders. Gastroenterology 2006;130:1459-1465.

8. Aziz Q, Fass R, Gyawali CP, Miwa H, Pandolfino JE, Zerbib F. Functional esophageal disorders. Gastroenterology 2016;150:1368-1379.

9. Kahrilas PJ, Quigley EM. Clinical esophageal pH recording: a technical review for practice guideline development. Gastroenterology 1996;110:1982-1996.

10. Savarino E, Tutuian R, Zentilin P, et al. Characteristics of reflux episodes and symptom association in patients with erosive esophagitis and nonerosive reflux disease: study using combined impedance-pH off therapy. Am J Gastroenterol 2010;105:1053-1061.

11. Pearson JP, Parikh S. Review article: nature and properties of gastro-oesophageal and extra-oesophageal refluxate. Aliment Pharmacol Ther 2011;33(Suppl 1):2-7.

12. Orlando RC. Review article: oesophageal tissue damage and protection. Aliment Pharmacol Ther 2011;33(Suppl 1):8-12.

13. Tutuian R, Castell DO. Review article: complete gastro-oesophageal reflux monitoring - combined $\mathrm{pH}$ and impedance. Aliment Pharmacol Ther 2006;24(Suppl 2):27-37.

14. Bredenoord AJ. Impedance-pH monitoring: new standard for measuring gastro-oesophageal reflux. Neurogastroenterol Motil 2008;20:434-439.

15. Zerbib F, Roman S, Ropert A, et al. Esophageal pH-impedance monitoring and symptom analysis in GERD: a study in patients off and on therapy. Am J Gastroenterol 2006;101:1956-1963. 
16. Mainie I, Tutuian R, Shay S, et al. Acid and non-acid reflux in patients with persistent symptoms despite acid suppressive therapy: a multicentre study using combined ambulatory impedance-pH monitoring. Gut 2006;55:1398-1402.

17. Savarino E, Zentilin P, Tutuian R, et al. The role of nonacid reflux in NERD: lessons learned from impedance-pH monitoring in 150 patients off therapy. Am J Gastroenterol 2008;103:2685-2693.

18. Savarino E, Marabotto E, Zentilin P, et al. The added value of impedance-pH monitoring to Rome III criteria in distinguishing functional heartburn from non-erosive reflux disease. Dig Liver Dis 2011;43:542-547.

19. Vela MF, Craft BM, Sharma N, Freeman J, Hazen-Martin D. Refractory heartburn: comparison of intercellular space diameter in documented GERD vs. functional heartburn. Am J Gastroenterol 2011;106:844-850

20. Savarino E, Zentilin P, Mastracci L, et al. Microscopic esophagitis distinguishes patients with non-erosive reflux disease from those with functional heartburn. J Gastroenterol 2013;48:473-482.

21. Slaughter JC, Goutte M, Rymer JA, et al. Caution about overinterpretation of symptom indexes in reflux monitoring for refractory gastroesophageal reflux disease. Clin Gastroenterol Hepatol 2011;9:868-874

22. Frazzoni M, Savarino E, Manno M, et al. Reflux patterns in patients with short-segment Barrett's oesophagus: a study using impedance$\mathrm{pH}$ monitoring off and on proton pump inhibitor therapy. Aliment Pharmacol Ther 2009;30:508-515.

23. Pritchett JM, Aslam M, Slaughter JC, Ness RM, Garrett CG, Vaezi MF. Efficacy of esophageal impedance/pH monitoring in patients with refractory gastroesophageal reflux disease, on and off therapy. Clin Gastroenterol Hepatol 2009;7:743-748.

24. Frazzoni M, Conigliaro R, Mirante VG, Melotti G. The added value of quantitative analysis of on-therapy impedance-pH parameters in distinguishing refractory non-erosive reflux disease from functional heartburn. Neurogastroenterol Motil 2012;24:141146, e87.

25. Frazzoni M, Conigliaro R, Melotti G. Reflux parameters as modified by laparoscopic fundoplication in 40 patients with heartburn/regurgitation persisting despite PPI therapy: a study using impedance-pH monitoring. Dig Dis Sci 2011;56:1099-1106.

26. Frazzoni M, Conigliaro R, Manta R, Melotti G. Reflux parameters as modified by EsophyX or laparoscopic fundoplication in refractory GERD. Aliment Pharmacol Ther 2011;34:67-75.

27. Frazzoni M, Piccoli M, Conigliaro R, Manta R, Frazzoni L, Melotti G. Refractory gastroesophageal reflux disease as diagnosed by impedance-pH monitoring can be cured by laparoscopic fundoplication. Surg Endosc 2013;27:2940-2946.

28. Farré R, Blondeau K, Clement D, et al. Evaluation of oesophageal mucosa integrity by the intraluminal impedance technique. Gut 2011;60:885-892.

29. Kessing BF, Bredenoord AJ, Weijenborg PW, Hemmink GJ, Loots CM, Smout AJ. Esophageal acid exposure decreases intraluminal baseline impedance levels. Am J Gastroenterol 2011;106:2093-2097.

30. Martinucci I, de Bortoli N, Savarino E, et al. Esophageal baseline impedance levels in patients with pathophysiological characteristics of functional heartburn. Neurogastroenterol Motil 2014;26:546-555.

31. de Bortoli N, Martinucci I, Savarino E, et al. Association between baseline impedance values and response proton pump inhibitors in patients with heartburn. Clin Gastroenterol Hepatol 2015;13:10821088.e1.

32. Helm JF, Dodds WJ, Pelc LR, Palmer DW, Hogan WJ, Teeter BC. Effect of esophageal emptying and saliva on clearance of acid from the esophagus. N Engl J Med 1984;310:284-288.

33. Shafik A, El-Sibai O, Shafik AA, Mostafa R. Effect of topical esophageal acidification on salivary secretion: identification of the mechanism of action. J Gastroenterol Hepatol 2005;20:1935-1939.

34. Frazzoni M, Manta R, Mirante VG, Conigliaro R, Frazzoni L, Melotti G. Esophageal chemical clearance is impaired in gastroesophageal reflux disease-a 24-h impedance- $\mathrm{pH}$ monitoring assessment. Neurogastroenterol Motil 2013;25:399-406.

35. Frazzoni M, Savarino E, de Bortoli N, et al. Analyses of the postreflux swallow-induced peristaltic wave index and nocturnal baseline impedance parameters increase the diagnostic yield of impedance-pH monitoring of patients with reflux disease. Clin Gastroenterol Hepatol 2016;14:40-46.

36. Frazzoni M, de Bortoli N, Frazzoni L, et al. Impairment of chemical clearance and mucosal integrity distinguishes hypersensitive esophagus from functional heartburn. $J$ Gastroenterol 2017;52:444-451.

37. Frazzoni M, De Bortoli N, Frazzoni L, et al. The added diagnostic value of postreflux swallow-induced peristaltic wave index and nocturnal baseline impedance in refractory reflux disease studied with on-therapy impedance-pH monitoring. Neurogastroenterol Motil 2017;29:e12947.

38. Patel A, Wang D, Sainani N, Sayuk GS, Gyawali CP. Distal mean nocturnal baseline impedance on $\mathrm{pH}$-impedance monitoring predicts reflux burden and symptomatic outcome in gastro-oesophageal reflux disease. Aliment Pharmacol Ther 2016;44:890-898.

39. Frazzoni L, Frazzoni M, De Bortoli N, et al. Postreflux swallowinduced peristaltic wave index and nocturnal baseline impedance can link PPI-responsive heartburn to reflux better than acid exposure time. Neurogastroenterol Motil 2017;29:e13116.

40. Penagini R, Sweis R, Mauro A, Domingues G, Vales A, Sifrim D. Inconsistency in the diagnosis of functional heartburn: usefulness of prolonged wireless $\mathrm{pH}$ monitoring in patients with proton pump inhibitor refractory gastroesophageal reflux disease. J Neurogastroenterol Motil 2015;21:265-272.

41. Savarino E, Pohl D, Zentilin P, et al. Functional heartburn has more in common with functional dyspepsia than with non-erosive reflux disease. Gut 2009;58:1185-1191.

42. de Bortoli N, Frazzoni L, Savarino EV, et al. Functional heartburn overlaps with irritable bowel syndrome more often than GERD. Am J Gastroenterol 2016;111:1711-1717.

43. Viazis N, Keyoglou A, Kanellopoulos AK, et al. Selective serotonin reuptake inhibitors for the treatment of hypersensitive esophagus: a randomized, double-blind, placebo-controlled study. Am J Gastroenterol 2012;107:1662-1667.

44. Limsrivilai J, Charatcharoenwitthaya P, Pausawasdi N, Leelakusolvong S. Imipramine for treatment of esophageal hypersensitivity and functional heartburn: a randomized placebocontrolled trial. Am J Gastroenterol 2016;111:217-224.

45. Mainie I, Tutuian R, Agrawal A, Adams D, Castell DO. Combined multichannel intraluminal impedance- $\mathrm{pH}$ monitoring to select patients with persistent gastro-oesophageal reflux for laparoscopic Nissen fundoplication. Br J Surg 2006;93:1483-1487.

46. Broeders JA, Draaisma WA, Bredenoord AJ, et al. Oesophageal acid hypersensitivity is not a contraindication to Nissen fundoplication. Br J Surg 2009;96:1023-1030.

47. Patel A, Sayuk GS, Gyawali CP. Parameters on esophageal pHimpedance monitoring that predict outcomes of patients with gastroesophageal reflux disease. Clin Gastroenterol Hepatol 2015; 13:884-891.

48. Desjardin M, Luc G, Collet D, Zerbib F. 24-hour pH-impedance monitoring on therapy to select patients with refractory reflux symptoms for antireflux surgery. A single center retrospective study. Neurogastroenterol Motil 2016;28:146-152.

49. Patel A, Sayuk GS, Kushnir VM, Chan WW, Gyawali CP. GERD phenotypes from $\mathrm{pH}$-impedance monitoring predict symptomatic outcomes on prospective evaluation. Neurogastroenterol Motil 2016;28:513-521. 
50. Patel A, Sayuk GS, Gyawali CP. Prevalence, characteristics, and treatment outcomes of reflux hypersensitivity detected on pH-impedance monitoring. Neurogastroenterol Motil 2016;28:1382-1390.

51. Fuchs KH, Babic B, Breithaupt W, et al; European Association of Endoscopic Surgery (EAES). EAES recommendations for the management of gastroesophageal reflux disease. Surg Endosc 2014;28:1753-1773.

52. Fock KM, Talley N, Goh KL, et al. Asia-Pacific consensus on the management of gastro-oesophageal reflux disease: an update focusing on refractory reflux disease and Barrett's oesophagus. Gut 2016;65:1402-1415.

53. Cremonini F, Ziogas DC, Chang HY, et al. Meta-analysis: the effects of placebo treatment on gastro-oesophageal reflux disease. Aliment Pharmacol Ther 2010;32:29-42.

54. Weijenborg PW, Cremonini F, Smout AJ, Bredenoord AJ. PPI therapy is equally effective in well-defined non-erosive reflux disease and in reflux esophagitis: a meta-analysis. Neurogastroenterol Motil 2012;24:747-757, e350.

55. Dent J, Vakil N, Jones R, et al. Accuracy of the diagnosis of GORD by questionnaire, physicians and a trial of proton pump inhibitor treatment: the Diamond Study. Gut 2010;59:714-721.

56. Frazzoni M, de Bortoli N, Frazzoni L, Tolone S, Savarino V, Savarino E. Impedance-pH monitoring for diagnosis of reflux disease: new perspectives. Dig Dis Sci 2017;62:1881-1889.

57. Molina-Infante J, Bredenoord AJ, Cheng E, et al; PPI-REE Task Force of the European Society of Eosinophilic Oesophagitis (EUREOS). Proton pump inhibitor-responsive oesophageal eosinophilia: an entity challenging current diagnostic criteria for eosinophilic oesophagitis. Gut 2016;65:524-531.

58. Rodrigo S, Abboud G, Oh D, et al. High intraepithelial eosinophil counts in esophageal squamous epithelium are not specific for eosinophilic esophagitis in adults. Am J Gastroenterol 2008; 103:435-442.

59. de Bortoli N, Penagini R, Savarino E, Marchi S. Eosinophilic esophagitis: update in diagnosis and management. Position paper by the Italian Society of Gastroenterology and Gastrointestinal Endoscopy (SIGE). Dig Liver Dis 2017;49:254-260.

60. Lucendo AJ, Molina-Infante J, Arias Á, et al. Guidelines on eosinophilic esophagitis: evidence-based statements and recommendations for diagnosis and management in children and adults. United European Gastroenterol J 2017;5:335-358.

61. Rohof WO, Salvador R, Annese V, et al. Outcomes of treatment for achalasia depend on manometric subtype. Gastroenterology 2013;144:718-725.

62. Savarino E, de Bortoli N, Bellini M, et al. Practice guidelines on the use of esophageal manometry - A GISMAD-SIGE-AIGO medical position statement. Dig Liver Dis 2016;48:1124-1135.

63. Zerbib F, Sifrim D, Tutuian R, Attwood S, Lundell L. Modern medical and surgical management of difficult-to-treat GORD. United European Gastroenterol J 2013;1:21-31.

64. Charbel S, Khandwala F, Vaezi MF. The role of esophageal $\mathrm{pH}$ monitoring in symptomatic patients on PPI therapy. Am J Gastroenterol 2005;100:283-289.

65. Savarino E, Zentilin P, Frazzoni M, et al. Characteristics of gastro-esophageal reflux episodes in Barrett's esophagus, erosive esophagitis and healthy volunteers. Neurogastroenterol Motil 2010;22:1061-e280. 